tions, including a new and detailed treatment of energy absorption in and near bone. An important new recommendation for radiotherapists is that the routine recording of bone doses and of tumour doses should now include a statement of maximum and minimum absorbed doses in rads. There is a section entitled "Report on an Inquiry on Current Errors in Clinical Dosimetry" which is somewhat disturbing; it should be carefully studied by all concerned.

In Part 3 ("Physical Aspects of Dosimetry") linear energy transfer and neutron dosimetry are treated in much greater detail, and there are entirely new sections on chemical, solid state, calorimetric and photographic dosimetry. The appendixes contain some interesting and often impressive accounts of international comparisons of various radioactivity standards, and it is noteworthy that Hönigschmid's weighings of radium standards, in which he estimated an error of about $0.02 \mathrm{mgm}$. (in around $20 \mathrm{mgm}$.), have now been accurately confirmed by ionization and calorimetric measurements. There are new appendixes on focal spots and the estimation of integral absorbed dose and the final appendix states the International Commission on Radiological Units and Measurements Position Plan adopted at Geneva in September 1958.
Many of the larger criticisms that could be raised against this report are now under active debate in preparation for the major revision referred to in the preface. In a composite production of this nature it is very difficult to preserve consistency. Thus, in referring to the calculated values of mass stopping power ratios $\left(s_{m}\right)$ in Table $8 \cdot 3$, it is stated in footnote 24 "... that an uncertainty of the order of 1 per cent exists in $s_{m}$..." yet later in the same section on page 37 it is recognized that the basis of these calculations is incorrect. The earlier admission on page 1 of errors ". . . of the order of a few per cent . . ." would appear to convey the requisite degree of caution. The symbolism is not always consistent and in some places (for example, p. 40 and Figs. 8.6 $b-d$ ), ' $E$ ' is used to denote particle kinetic energy, whereas in other places (for example, p. 51 and Figs. 8.3 $a-c$ ), ' $T$ ' is used for the same purpose.

It is almost superfluous to add that this Handbook is essential reading for all radiation physicists, radiotherapists, radiologists and radiobiologists. Unfortunately it is rather unattractively produced, it has several misprints and grammatical errors, and the numerous footnotes are scarcely legible without the aid of magnification. P. R. J. BURCH

\title{
THE RED DEER COMMISSION
}

$\mathrm{T}$ HE Red Deer Commission was constituted in October 1959 with the general aim of furthering the conservation and control of red deer in Scotland. Its setting up marked the first comprehensive attempt to deal with a controversial problem which has vexed the Highlands for the best part of two centuries.

The introduction of large-scale sheep farming into the Highlands in the latter half of the eighteenth century, replacing the old population of farmers with their primitive breeds of cattle and sheep, resulted, towards the end of that century, in the reduction of deer stocks to probably their lowest level. At the beginning of the nineteenth century another influence was introduced by the develop. ment of the sport of stalking, giving a new value to the deer. When prices of wool and mutton declined towards the end of that century, the area given over to deer forests increased rapidly, from less than two million acres in $\mathbf{1 8 8 3}$ to more than three and a half million acres at its peak in 1912 . In 1952, however, the area of deer forests was estimated to have been reduced to about three million acres.

The influence of these developments on the range and population of deer affected every aspect of highland life, causing deep dissensions. Between 1872 and 1952 six different committees or commissions were appointed by Parliament to make recommendations with regard to conservation and control, but little or nothing was achieved until 1939. The Deer and Ground Game (Scotland) Bill introduced in that year provided powers to control deer, to be exercised by the Department of Agriculture with the assistance of an Advisory Committee and local committees. Developments were prevented by the War, and it was not until 1959 that an Act of Parliament was passed to introduce close seasons for deer in Scotland.

The Act is divided into five parts. Part 1 deals with the setting up of a Commission and its powers.
Part 2 specifies close seasons for stags during October 21-June 30 and for hinds during February 16October 20, to come into force on October $21,1962$. The Commission has now issued its first report*, and, in it, states that, "we consider that if viable stocks of deer are to be maintained throughout the traditional deer forest areas of the Highlands they should not be broken up into isolated fragments. At the same time, if they are not to continue as a serious liability to agriculture and forestry, they must be kept under control. In other words, as grazing animals they should be subject to reasonable standards of management."

The numbers and population densities of deer, unlike those of many other wild animals, do not appear to be self-limiting. In the absence of natural predators such as wolves, or of sufficient killing, deer will increase until they overgraze and damage their habitat, die in large numbers from starvation, or overspill on to agricultural land. Persistent overgrazing must lead to the progressive impoverishment of the hill pastures, on which they depend for their food, and a declining productivity. For the past two centuries, man has provided the only check against this deterioration. The fact that he has not everywhere been exercising sufficient control is the prime reason for the setting up of the Red Deer Commission, with certain over-riding powers, including authority to go on private land in the exercise of its functions.

During the period under review, the Commission has been concerned primarily with the control of marauding deer. Experience this year has shown that it is both widespread and continuous. Where estates are under good management, effective measures are taken to protect tenants and neigh-

* The Red Deer Commission. Report for the period 1st October 1959, to 31st December, 1960. Pp. 22. (London: H.M. Stationery
Office, 1961.) 18. 3d. net. 
bours from damage. There are, however, areas where much more could be done to protect those who suffer. In general, where the laird or factor is permanently resident, satisfactory co-operation and understanding are most easily achieved. Where there is no one of sufficient authority to deal with it on the spot, and the estate concerned is factored from an office outside the Highlands, it is inevitably more difficult.

In some areas where marauding is prevalent there are not enough stalkers and gamekeepers available to deal with the situation. The Commission believes that the widespread marauding taking place throughout the year is probably a symptom of overstocking on recognized deer land in the vicinity, and that the root of all deer 'trouble' is lack of adequate management. The annual kill of hinds, for example, is generally too low ; the only way to reduce overlarge stocks is in the culling of hinds. When it is left to an inadequate staff of stalkers or gamekeepers this most important aspect of management is apt to go by default. Sometimes, excessive stocks of deer have been maintained to make allowance for the slaughter done by gangs of poachers. Whatever justification there may have been for this practice in the past, it no longer exists.

Estates in some areas are seriously handicapped in stag shooting by the incursion of the public in the later summer and autumn. If such estates are to be enabled to carry out their obligations during the open (stalking) season, means will have to be found to dissuade the public from disturbing the ground and possibly courting danger to themselves.

\section{WOMEN ENGINEERS IN THE U.S.S.R.}

W OMEN form a much higher proportion of engineers and technologists in the U.S.S.R. than in Western Europe or the United States. A study arranged by the Caroline Haslett Memorial Trust was designed to throw light on the factors giving rise to this high proportion, on the capability of women to benefit from a technical education, and on the employment prospects of women so trained. The study included an investigation in the U.S.S.R. itself, and this was undertaken by Miss L. S. Souter, head of the Magnetic Materials Section of the Associated Electrical Industries Research Laboratory, Harlow, and Miss R. Winslade, assistant instruments group manager, Research and Control Instruments, Ltd.

In their report* the authors show that, under the national educational system of the U.S.S.R., coeducation of boys and girls is the general practice. In 1943 the sexes were separated into different schools, but, after a ten-year trial, the experiment was abandoned under pressure of public opinion. Only one trace of the separation remains; while boys of 11-14 are having carpentry lessons, girls are being taught domestic science. For all other subjects boys and girls attend the same classes, and, with few exceptions, girls have the same choice of specialities as boys. Comparisons of the performance of men and women as engineers have been made easier by this common educational background. Although the right of entry into university was not fully extended to women until after the 1917 revolution, the limited right of attendance at higher educational courses (some specially cet up for women) was granted in 1905 as a result of revolutionary developments at that time and, by 1907, a number of technical institutions were open. There are records of women attending engineering classes at polytechnics during 1907-9, but the numbers were comparatively small.

Equality of opportunity brought the proportion of women in some of the universities up to 50 per cent in 1920. While at the higher medical schools 80-85 per cent of the students were women, the entry into the engineering schools appears to have been much slower. Even as late as 1928, only 1 per

* Caroline Haslett Memorial Trust. Women Engineers in the U.S.S.R.: a Study of the Education, Employment and Prospects of Women Engineers in the the Caroline Haslett the Place, W.1, 1960). cent of the students of thermal power were women; the proportions of women students taking chemistry, physics and mathematics courses was much higher.

The rate of entry of girls into engineering at a lower level appears to have been somewhat faster, and was encouraged by the all-out drive to make good the technical backwardness of the country as a whole. By 1929, 37.1 per cent of pupils at the technicums or trade schools were girls.

In the middle 1930's the entry of girls into engineering institutes increased gradually and then rapidly, partly as a result of the drive to develop industry throughout the country. By 1938 about 28 per cent of the engineoring students were women, and by the end of the decade the 30 per cent mark appears to have been passed. Young men were sharing engineering classes with a high proportion of girls and were taught by staffs which in 1939 included 23 per cent women. They came to take it for granted that engineering was not only a possible but also a suitable profession for women.

The increasing proportion of women students in engineering institutes continued after the Second World. War, but the rate of increase was falling; the numbers are now increasing slowly, and there has been negligible change in the $33-35$ per cent level reached in the late 1940 's. There has, however, been a considerable increase in the number of women holding higher engineering qualifications. The industries which attract women engineers show marked differences from Great Britain. Here, industries with a long tradition of women operatives are slow to attract (or accept) women engineers; in the U.S.S.R. it is the textile and food industries which have the highest proportion of women engineers. The high proportion of women engineers in the U.S.S.R. was so much taken for granted that the reasons for the Souter-Winslade study were frequently called into question and led to no little amusement.

Throughout the U.S.S.R. women are forbidden to take up any branch of engineering which is considered to be prejudicial to health. Some examples are: (1) at trade-level-girls are not permitted to service television sets because of the danger of radia. tion and because of the heavy weights of the sets themselves; they are permitted to train as telephone service engineers, but not allowed to carry out work involving the climbing of roofs or poles, or to work 